\title{
Assessment of Antioxidant Activity and Neuroprotective Capacity on PC12 Cell Line of Frankenia thymifolia and Related Phenolic LC-MS/MS Identification
}

\author{
Rim Ben Mansour, ${ }^{1}$ Wided Megdiche Ksouri, ${ }^{1}$ Stéphanie Cluzet, ${ }^{2}$ Stéphanie Krisa, ${ }^{2}$ \\ Tristan Richard, ${ }^{2}$ and Riadh Ksouri ${ }^{1}$ \\ ${ }^{1}$ Laboratory of Aromatic and Medicinal Plants, Center of Biotechnology, Technopark of Borj-Cedria (CBBC), BP 901, \\ 2050 Hammam-Lif, Tunisia \\ ${ }^{2}$ University of Bordeaux, ISVV, GESVAB EA3675, 33882 Villenave d'Ornon, France
}

Correspondence should be addressed to Riadh Ksouri; ksouri.riadh@gmail.com

Received 20 July 2016; Revised 23 September 2016; Accepted 28 September 2016

Academic Editor: Gabriel A. Agbor

Copyright (C) 2016 Rim Ben Mansour et al. This is an open access article distributed under the Creative Commons Attribution License, which permits unrestricted use, distribution, and reproduction in any medium, provided the original work is properly cited.

\begin{abstract}
This work aimed to investigate the richness of a Tunisian xerohalophyte Frankenia thymifolia aerial and root parts on phenolics and to evaluate the antioxidant and neuroprotective properties of this medicinal species. After fractionation using increasing and different solvent polarities, results displayed five fractions, where ethyl acetate (EtOAc) shoot and root fractions possess considerable total phenolic contents ( 221 and $308 \mathrm{mg}$ of GAE/g of E, resp.) related to their important antioxidant activities such as ORAC (918 and $713 \mathrm{mg}$ of TE/g of E), DPPH (282 and $821 \mathrm{mg}$ of TE/g), and ABTS (778 and $1320 \mathrm{mg}$ of TE/g) tests. Then, the identification of the main compounds by HPLC-DAD-ESI-MS and neuroprotective property of the most active fraction EtOAc were assessed. A total of 14 molecules were identified, which have been described for the first time in F. thymifolia. The major compounds identified were pinoresinol and kaempferol glycoside in aerial parts and gallic acid and ellagitannin in roots. Neuroprotective capacity against $\beta$ amyloid $(\mathrm{A} \beta)$ peptide induced toxicity in PC12 cells of EtOAc fraction showed a significant protective activity at lower concentration $(25$ and $50 \mu \mathrm{M})$. The relevant antioxidant and neuroprotective activities of $F$. thymifolia EtOAc fraction corroborated their chemical compositions.
\end{abstract}

\section{Introduction}

Many lifestyle factors endorse health of the nervous system in trouble by imposing a mild stress on neural cells and demand for phytotherapeutic agents is growing, in view of synthetic drugs that are believed to have certain side effects such as dry mouth, tiredness, anxiety or nervousness, dementia, and pseudodementia [1]. Effects of these synthetic drugs have caught attention from research bases and industries towards natural herbal resources [2]. In addition to their antioxidant and several health promoting activities, natural bioactive compounds including phenolics, flavonoids, alkaloids, terpenoids, lignans, and saponins have potential properties to modulate neuronal function, protective mechanism against neurodegeneration, and memory enhancing properties and attenuate the damaging effects of reactive oxygen species
(ROS). Many factors are known to play a direct role in the initiation of neurodegeneration; free radical formation by ROS is the main causative factor [3]. Excess of ROS in the body can lead to cumulative damage in cellular structures, resulting in so-called oxidative stress [4]. Neurons and brain cells are particularly vulnerable to free radicals, and oxidative stress is one of the main causative factors in the etiology of a number of late onset disorders $[1,5]$. In addition, oxidative stress seems to mediate $\beta$-amyloid peptide toxicity by free radical production, suggesting a pathophysiological relation between $\mathrm{A} \beta$ and imbalance between reactive oxygen production and protective system [6]. Neuronal cells oxidative damage may be a source of endogenous production of ROS, and amyloid beta $(\mathrm{A} \beta)$ peptide may increase ROS production causing further impairment of cellular structure function in brain $[7,8] . A \beta$ is the main component of senile plaques and 
is highly involved in the progression of neurodegenerative diseases and impairment activity of several complexes of mitochondrial respiratory chain in neurons and astrocytes [8]. Finding molecules such as phenolics play a major part in inhibition of propagation of oxidative chain reaction and in maintaining the brain's chemical balance by acting upon the function of receptors for the major inhibitory neurotransmitters [1]. These compounds prevent aggregation and attenuate $\mathrm{A} \beta$-induced toxicity, protein oxidation, and apoptosis in primary hippocampal cultures $[9,10]$. In Tunisia, considerable diversity of folkloric medicinal halophytes (spontanoeus plants) is known for their ability to withstand and quench these toxic ROS and for their strong biological properties, sometimes exceeding many natural antioxidants from medicinal cultivated species (glycophytes). Among them, Frankenia thymifolia belonging to Frankeniaceae family is an endemic species from North Africa. Wided et al. [11] reported that F. thymifolia exhibit high polyphenol, flavonoid and tannin contents, and antioxidant and antibacterial activities. Phytochemical studies on the genus Frankenia and the information on the chemical composition of $F$. thymifolia are still scarce. There are only studies that address the identification of pinoresinol 4-sulfate, lignan sulfate, and two aromatic compounds (1,2,3,4,5,7-hexamethoxynaphthalene and 4,5dimethoxy-3-hydroxybenzoate methyl) in F. thymifolia Desf. [12].

Due to the importance of identifying new compounds with interesting antioxidant and biological activities, we describe the optimization of aerial parts and roots fractionation of $F$. thymifolia using solvents with increasing polarity. The crude extracts and obtained fractions were evaluated in terms of their antioxidant properties through different antioxidant tests such as DPPH, ABTS, metal chelating activity (MCA), and ORAC. In addition, the neuroprotective activity against $\beta$-amyloid peptide on PC12 cell line and the investigation of phytochemical composition of EtOAc fractions by using HPLC-DAD-MS/MS were assessed.

\section{Materials and Methods}

2.1. Plant Material and Extraction. F. thymifolia was collected during the vegetative stage in March 2014 from Borj-Cedria (latitude: $36^{\circ} 46^{\prime} \mathrm{N}$ and longitude: $10^{\circ} 39^{\prime} \mathrm{E}$ ) at $30 \mathrm{Km}$ to Tunis. This halophyte was identified at the Biotechnology Centre (CBBC, Technopark of Borj-Cedria), and a voucher specimen [PLM52] was deposited at the Herbarium of the Laboratory of Medicinal and Aromatic Plants at the CBBC. After air drying, aerial parts and root extracts were obtained by magnetic stirring of $150 \mathrm{~g}$ of matter powder with $1500 \mathrm{~mL}$ methanol $80 \%$ for $2 \mathrm{~h}$; then the filtrate is evaporated using a rotary evaporator. The obtained filtrate is first extracted with hexane followed by dichloromethane, ethyl acetate, and finally butanol. The different phases are separated by a separatory funnel.

2.2. Total Phenolic Contents. Total phenolic contents (TPC) of aerial part and root extracts were determined by the FolinCiocalteu colorimetric method [13] adapted to 96-well plate.
To $20 \mu \mathrm{L}$ of extract $(1 \mathrm{mg} / \mathrm{mL}), 100 \mu \mathrm{L}$ of Folin-Ciocalteu's reagent was added. After $2-3 \mathrm{~min}, 80 \mu \mathrm{L}$ of sodium carbonate $(75 \mathrm{~g} / \mathrm{L})$ solution was added. After $1 \mathrm{~h}$, the absorbance was measured at $765 \mathrm{~nm}$. The TPC was expressed as $\mathrm{mg}$ of gallic acid equivalent per $\mathrm{g}$ of extract (mg of GAE/g of E). Experiments were analyzed at least three times and with triplicate samples.

2.3. Radical Scavenging Assay. Radical scavenging ability against DPPH radical was measured as described by Blois [14]. A volume of $50 \mu \mathrm{L}$ of each sample $(1 \mathrm{mg} / \mathrm{mL})$ was mixed with $150 \mu \mathrm{L}$ of $200 \mu \mathrm{M}$ methanolic solution of DPPH in a 96well plate. The plate was allowed to stand in dark for $20 \mathrm{~min}$. The absorbance was measured at $520 \mathrm{~nm}$.

The scavenging activity of the extracts on ABTS radical cation was estimated according to the method of Re et al. [15]. Briefly, $250 \mu \mathrm{L}$ of the diluted $\mathrm{ABTS}^{+}$solution was added to $10 \mu \mathrm{L}$ of extracts at the concentration of $1 \mathrm{mg} / \mathrm{mL}$ (or Trolox). Six minutes after initial mixing, the absorbance was measured at $734 \mathrm{~nm}$ at $30^{\circ} \mathrm{C}$. Results were expressed as $\mathrm{mg}$ of TE/g of E. All samples were analyzed in triplicate in at least three different experiments.

2.4. Metal Chelating Activity (MCA). The chelating activity of the extracts for ferrous ions $\mathrm{Fe}^{+2}$ was measured according to the method of Dinis et al. [16]. A volume of $80 \mu \mathrm{L}$ of deionized water and $40 \mu \mathrm{L}$ of $\mathrm{FeSO}_{4}(0.2 \mathrm{mM})$ were added to extract $(40 \mu \mathrm{L}, 1 \mathrm{mg} / \mathrm{mL})$ and mixed in 96-well microplate. The reaction was initiated by addition of $40 \mu \mathrm{L}$ of ferrozine $(2 \mathrm{mM})$. The absorbance of $\mathrm{Fe}^{2+}$-ferrozine complex was measured at $562 \mathrm{~nm}$ after $10 \mathrm{~min}$. EDTA was used as standard and results were expressed as mg of EDTA per gram of extract (mg of EDTA/g of E). All samples were analyzed in triplicate in at least three different experiments.

2.5. ORAC Assay. The procedure was modified from the method described by Ou et al. [17], using Trolox as a control standard. The ORAC assay was carried out in black round bottom 96-well microplates (Costar) and absorbance was measured with an automated plate reader (Fluostar Optima, BMG Labtech). All the samples (extracts, fluorescein, and AAPH) were diluted in $75 \mathrm{mM}$ phosphate buffer ( $\mathrm{pH} 7.4$ ). Thirty microliters of each extract $(1 \mathrm{mg} / \mathrm{mL})$ or phosphate buffer (blank) was mixed with $180 \mu \mathrm{L}$ of fluorescein solution (117 nM final concentrations) and incubated for $5 \mathrm{~min}$ at $37^{\circ} \mathrm{C}$. A volume of $90 \mu \mathrm{L}$ of AAPH solution ( $40 \mathrm{mM}$ final concentration) was added and fluorescence was immediately monitored using $485 \mathrm{~nm}$ excitation and $520 \mathrm{~nm}$ emission wavelengths at $1 \mathrm{~min}$ intervals for $70 \mathrm{~min}$. The antioxidant capacities of the extracts were expressed as mg of Trolox equivalent per $g$ of extract (mg of TE/g of E). All samples were analyzed in quadruplicate and at least in three different experiments.

2.6. Cell Culture and MTT Assay of Shoot and Root EtOAc Fraction. Pheochromocytoma-derived PC12 cells (ATCC, Manassas, VA, USA) were maintained routinely in DMEMGlutamax supplemented with $15 \%$ horse serum, $2.5 \%$ fetal bovine serum, and $1 \%$ penicillin/streptomycin antibiotics at 
$37^{\circ} \mathrm{C}$ in humidified atmosphere of $5 \% \mathrm{CO}_{2} / 50 \%$ air. Cells were plated at a density of 30.000 cells per well in 96-well plates and incubated at $37^{\circ} \mathrm{C}$ for $24 \mathrm{~h}$. Then, the cells were treated with $5 \mu \mathrm{M}$ of $\mathrm{A} \beta_{(25-35)}$, with or without extracts at $25,50,100,200$, and $300 \mu \mathrm{M}$ in serum-free culture medium. After $24 \mathrm{~h}$ of incubation, cell viability was determined by the conventional MTT reduction assay. Cells were treated with MTT solution $(0.5 \mathrm{mg} / \mathrm{mL})$ for $3 \mathrm{~h}$ at $37^{\circ} \mathrm{C}$. The dark blue formazan crystals formed in viable cells were solubilized with DMSO for $0.5 \mathrm{~h}$. The absorbance was measured at $595 \mathrm{~nm}$ with a microplate reader (Dynex, USA). Results were expressed as the percentage of MTT reduction in relation to the absorbance of control cells at $100 \%$. All data represent the average of four tests.

2.7. HPLC-DAD-ESI-MS. Lyophilised EtOAc fractions were dissolved in 50\% methanol and chromatographed using HPLC-DAD-ESI-MS system. The chromatography apparatus was Agilent 1200 from Agilent Technologies (Santa Clara, CA, USA). The EtOAc fractions were analyzed at $25^{\circ} \mathrm{C}$ with a $250 \times 4 \mathrm{~mm}$ i.d. $5 \mu \mathrm{m}$, Prontosil $120-5-\mathrm{Cl}$-AQ reverse phase column (Bischoff, Leonberg, Germany). Water, 0.1\% $\mathrm{HCOOH}$ (solvent A), and acetonitrile $0.1 \% \mathrm{HCOOH}$ (solvent $\mathrm{B})$ were used as mobile phases. The gradient elution program was as follows (v/v): 0 min $1 \%$ B, 0.4 min $1 \%$ B, 2 min $10 \%$ B, $6 \min 35 \% \mathrm{~B}, 7 \min 50 \% \mathrm{~B}, 8.8 \mathrm{~min} 70 \% \mathrm{~B}, 10.8 \mathrm{~min}$ $92 \% \mathrm{~B}, 11 \mathrm{~min} 100 \% \mathrm{~B}$, and $12 \mathrm{~min} 100 \% \mathrm{~B}$, followed by 10 min for reequilibration. The optimum values of the ESIMS parameters were as follows: capillary voltage, $-4.7 \mathrm{kv}$; drying gas temperature, $350^{\circ} \mathrm{C}$; drying gas flow, $10 \mathrm{~L} / \mathrm{min}$; nebulising gas pressure, $35 \mathrm{psi}$. LC/MS accurate mass spectra were recorded across the range $150-2000 \mathrm{~m} / z$. The detection wavelengths were set at 280 and $360 \mathrm{~nm}$. LC-ESI-MS analyses were carried out in the negative ion mode. This HPLC was coupled to Esquire 3000+ ion trap mass spectrometer using ESI source from Bruker Daltonics (Billerica, MA, USA).

2.8. Statistical Analysis. Results are expressed as means \pm standard deviation of three replicates. Multiple sample comparison was performed using the Statgraphics Plus program version 5.1 for windows. Analysis of variance (ANOVA) followed by Duncan's multiple comparison test was used. Whenever ANOVA could not be used, Kruskal-Wallis test was applied after checking for normal distribution of the groups and homogeneity of variances. The level of significance was $P<0.05$. In order to compare the different values of antioxidant activities obtained in our extracts after all types of antioxidant measurement, the Pearson correlation test was used. Alternatively, the results were analyzed by GraphPad Prism 5.03 for Windows (GraphPad Software, San Diego, CA, USA).

\section{Results and Discussion}

3.1. Total Phenolic Content. Methanolic crude extract and five fractions (hexane, dichloromethane, ethyl acetate, butanol, and water) of $F$. thymifolia aerial parts and roots were analyzed for total phenolic contents (TPC) and reported in Table 1. TPC were higher in root than in aerial parts and varied significantly as function of solvent. The highest recovery of TPC was observed in ethyl acetate fraction reaching up to 221 and $308 \mathrm{mg} \mathrm{GAE} / \mathrm{g}$ in aerial part and root, respectively, while the lower recovery was observed in hexane fraction ( $13 \mathrm{mg}$ of $\mathrm{GAE} / \mathrm{g}$ for aerial parts and $55 \mathrm{mg}$ of GAE/g for roots). However, given the low polarity of EtOAc (polarity index 4.4) when compared with butanol, methanol (5.1), or water (polarity index 9), it seems logical to suppose that the highest recovery of TPC by using EtOAc was presumably due to its high molecular weight $(88 \mathrm{~g} / \mathrm{moL})$ which enable it to easily extract about the same molecular weight following the concept "like dissolves like." Fernandes de Oliveira et al. [18] reported that ethyl acetate phase of Sidastrum micranthum (Malvaceae) had the highest content of TPC (177.44 mg of GAE/g) compared to other phases such as butanol, water, dichloromethane, and hexane. These data highlight that the solubility of the phenolics is governed by solvent polarity, degree of polymerization of phenolics, and the part of the plant used [19].

3.2. Antioxidant Activities. In the objective of choosing the adequate solvent for antioxidant capacity, DPPH, ABTS, ORAC, and MCA tests were used to evaluate the electron transfer and the hydrogen atom transfer capacity of each F. thymifolia fraction. Results depicted that root fractions exhibit better performances than aerial part against DPPH radical. Moreover, F. thymifolia was found to possess a significant variability in its inhibitory activity against this radical as a solvent function (Table 1). The EtOAc fraction is still the most active with 282 and $821 \mathrm{mg}$ of TE/g of $\mathrm{E}$ for aerial parts and roots, respectively. Fernandes de Oliveira et al. [18] also found that the EtOAc fraction of Sida rhombifolia (Malvaceae family) exhibits the highest antiradical activity as compared to hexane, dichloromethane, butanol, and water fractions. Anagnostopoulou et al. [20] showed also that the higher radical scavenging activities were found for the ethyl acetate fraction of sweet orange peel (Citrus sinensis). In the same context, Cakir et al. [21] showed that ethyl acetate fraction exhibited the highest DPPH radical scavenging activity from the aerial parts of Hypericum hyssopifolium L. These data are in agreement with previous study of Saada et al. [22], which showed that EtOAc fraction of the halophyte Retama raetam (Fabaceae family) exhibits the highest total phenolic compounds and antioxidant activity.

Results consigned in Table 1 revealed also that scavenging ability of ABTS radical of the aerial part fractions is less active than root fractions. Independent of the organ, EtOAc fraction displayed the higher ability to quench $\mathrm{ABTS}^{+\bullet}$ free radical in aerial part and root $(778 \mathrm{mg}$ of TE/g of E; $1320 \mathrm{mg} \mathrm{TE} / \mathrm{g}$ of $\mathrm{E}$, resp.). Total phenolics generally correlate with antioxidant capacities as measured by the ABTS or DPPH methods [23].

Measuring the ability of oxygen radical absorbance capacity (ORAC) was widely used in the field of antioxidants and oxidative stress. The antioxidative potential of different fractions evaluated by ORAC indicated that EtOAc fraction is the most active (918 and $713 \mathrm{mg}$ TE/g in aerial parts and roots, resp.). Though, hexane fraction of aerial parts showed very 
TABLE 1: Total phenolic content (TPC) and antioxidant assays of Frankenia thymifolia aerial parts and root fractions (crude extract; hexane fraction; dichloromethane fraction; EtOAc fraction; $\mathrm{BuOH}$ fraction; water fraction).

\begin{tabular}{|c|c|c|c|c|c|}
\hline & $\begin{array}{c}\text { TPC } \\
\text { (mg of GAE/g) }\end{array}$ & $\begin{array}{c}\text { DPPH } \\
\text { (mg of TE/g) }\end{array}$ & $\begin{array}{c}\text { ABTS } \\
\text { (mg of TE/g) }\end{array}$ & $\begin{array}{c}\text { ORAC } \\
\text { (mg of } \mathrm{TE} / \mathrm{g})\end{array}$ & $\begin{array}{c}\text { MCA } \\
\text { (mg of EDTA } / g \text { ) }\end{array}$ \\
\hline \multicolumn{6}{|l|}{ Aerial parts } \\
\hline Methanolic extract & $87 \pm 7^{\mathrm{c}}$ & $132 \pm 21^{c}$ & $154 \pm 11^{\mathrm{e}}$ & $305 \pm 40^{\mathrm{c}}$ & $16 \pm 2^{\mathrm{c}}$ \\
\hline Hexane & $13 \pm 4^{\mathrm{e}}$ & $37 \pm 4^{\mathrm{e}}$ & $88 \pm 3^{\mathrm{f}}$ & $63 \pm 18^{\mathrm{e}}$ & $26 \pm 3^{\mathrm{b}}$ \\
\hline Dichloromethane & $75 \pm 5^{\mathrm{d}}$ & $86 \pm 17^{\mathrm{d}}$ & $211 \pm 20^{\mathrm{d}}$ & $324 \pm 51^{c}$ & $24 \pm 1^{\mathrm{b}}$ \\
\hline Ethyl acetate & $221 \pm 11^{\mathrm{a}}$ & $282 \pm 22^{\mathrm{a}}$ & $778 \pm 27^{\mathrm{a}}$ & $918 \pm 84^{\mathrm{a}}$ & $39 \pm 2^{\mathrm{a}}$ \\
\hline Butanol & $160 \pm 7^{b}$ & $235 \pm 15^{b}$ & $604 \pm 36^{\mathrm{b}}$ & $498 \pm 48^{\mathrm{b}}$ & $25 \pm 5^{b}$ \\
\hline Water & $83 \pm 7^{c}$ & $136 \pm 27^{\mathrm{c}}$ & $321 \pm 43^{c}$ & $174 \pm 14^{\mathrm{d}}$ & $26 \pm 3^{b}$ \\
\hline \multicolumn{6}{|l|}{ Roots } \\
\hline Methanolic extract & $216 \pm 11^{b}$ & $421 \pm 61^{b}$ & $792 \pm 64^{\mathrm{b}}$ & $386 \pm 57^{\mathrm{bc}}$ & $16 \pm 2^{b}$ \\
\hline Hexane & $55 \pm 9^{\mathrm{f}}$ & $67 \pm 13^{c}$ & $120 \pm 10^{\mathrm{e}}$ & $463 \pm 43^{\mathrm{b}}$ & $1 \pm 1^{\mathrm{e}}$ \\
\hline Dichloromethane & $111 \pm 12^{\mathrm{e}}$ & $125 \pm 17^{c}$ & $264 \pm 34^{\mathrm{d}}$ & $468 \pm 57^{\mathrm{b}}$ & $5 \pm 2^{\mathrm{d}}$ \\
\hline Ethyl acetate & $308 \pm 6^{\mathrm{a}}$ & $821 \pm 74^{\mathrm{a}}$ & $1320 \pm 63^{\mathrm{a}}$ & $713 \pm 100^{\mathrm{a}}$ & $22 \pm 2^{\mathrm{a}}$ \\
\hline Butanol & $152 \pm 8^{\mathrm{d}}$ & $420 \pm 87^{\mathrm{b}}$ & $697 \pm 40^{c}$ & $303 \pm 61^{c}$ & $14 \pm 2^{\mathrm{c}}$ \\
\hline Water & $175 \pm 7^{\mathrm{c}}$ & $430 \pm 82^{\mathrm{b}}$ & $797 \pm 36^{\mathrm{b}}$ & $420 \pm 59^{\mathrm{b}}$ & $17 \pm 2^{\mathrm{b}}$ \\
\hline
\end{tabular}

${ }^{\mathrm{a}-\mathrm{f}}$ Significant difference at $P<0.05$ by Tukey's test.

low peroxyl radical scavenging activity, which was around 15 times lesser than EtOAc fraction (Table 1). In this context, Surget et al. [24] observed that EtOAc fraction of the halophyte Salicornia ramosissima showed high ORAC activity. Lizcano et al. [25] showed that ABTS and ORAC antioxidant activity values increased with increasing polyphenol content of the plant extracts.

The metal chelating activities (MCA) of the Frankenia fractions were monitored in order to evaluate the ability to inhibit interactions between metals and lipids. Overall, iron chelating activities were higher in aerial part fractions than in root. EtOAc fractions showed the higher activity (39 and $22 \mathrm{mg}$ EDTA/g for aerial parts and roots, resp.). High iron levels may act catalytically to produce reactive oxygen species (Fenton reaction), with a negative impact on the structure and function of cells [26]. Iron can promote the formation of hydroxyl radicals and decompose lipid hydroperoxides into highly reactive lipid alkoxyl and peroxyl radicals, which perpetuate the chain reaction of lipid peroxidation $[26,27]$. Many reports showed in this context the influence of the solvent on the capacity of extracts to chelate $\mathrm{Fe}^{2+}[28]$.

On the other hand, positive and strong correlations $(r>$ 0.9) were found between TPC and each of the antioxidant assays (DPPH, ABTS, ORAC, and MCA) used in both aerial part and root of $F$. thymifolia (Table 3), which indicated that polyphenols in $F$. thymifolia extracts are largely responsible for the antioxidant activities. However, no correlation was found for ORAC and MCA tests in root and aerial part, respectively. A study performed by Babbar et al. [29] showed that phenolic contents alone are not fully responsible for the antioxidant activity of plants. Other constituents such as ascorbate, reducing carbohydrates, tocopherols, carotenoids, terpenes, and pigments as well as the synergistic effect among them could possibly contribute to the metal chelating activity.
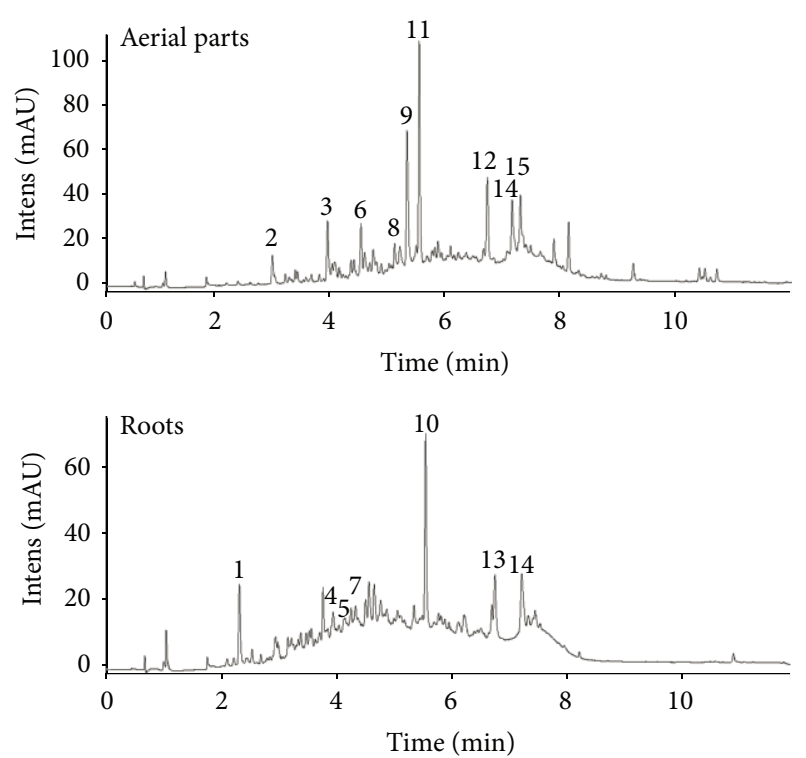

FIGURE 1: HPLC-DAD-ESI-MS base peak chromatograms in negative ion mode and UV at $280 \mathrm{~nm}$ for the ethyl acetate fraction of aerial parts and roots of $F$. thymifolia.

3.3. HPLC-DAD-ESI-MS. In next study, identification of the predominant compounds of EtOAc fractions from aerial and root parts was assessed by HPLC-DAD-ESI-MS in negative mode (Figure 1). For the first time, the methodology used in this work allowed us to identify 14 new phenolic compounds. All of them have not been described so far in F. thymifolia. The compounds detected in this work were tentatively characterized by means of MS data, together with the interpretation of the observed MS-MS spectra in comparison with those found in the literature and public databases (Table 2). 
TABLE 2: Phenolic compounds detected in ethyl acetate fraction by HPLC-DAD-ESI-MS from aerial parts and roots of F. thymifolia in negative mode.

\begin{tabular}{lcccccc}
\hline Peak number & $\mathrm{RT}(\mathrm{mn})$ & $\lambda_{\max }(\mathrm{nm})$ & {$[\mathrm{M}-\mathrm{H}]^{-}$} & Fragments & Organ & Tentative Identification \\
\hline $\mathbf{1}$ & 2.3 & 275 & 169 & 125 & $\mathrm{R}$ & Gallic acid \\
$\mathbf{2}$ & 3 & 310 & 153 & 123 & AP & Hydroxytyrosol \\
$\mathbf{3}$ & 3.9 & $280 / 310$ & 137 & 93 & AP & Hydroxybenzoic $p$-acid \\
$\mathbf{4}$ & 3.9 & 280 & 609 & $483-441-423-305$ & $\mathrm{R}$ & Prodelphinidin B-4 \\
$\mathbf{5}$ & 4.2 & 280 & 635 & 465 & $\mathrm{R}$ & Trigalloyl hexoside \\
$\mathbf{6}$ & 4.5 & 280 & 333 & $289-265$ & AP & Posthumulone \\
$\mathbf{7}$ & 4.5 & 280 & 449 & $287-431$ & $\mathrm{R}$ & Luteolin 7-O-glucoside \\
$\mathbf{8}$ & 5.3 & $260 / 360$ & 463 & $301,178,151$ & AP & Hyperoside \\
$\mathbf{9}$ & 5.5 & $260 / 360$ & 357 & 329 & AP & Pinoresinol \\
$\mathbf{1 0}$ & 5.5 & $290 / 320$ & 497 & $344-402-449-482$ & $\mathrm{R}$ & Unknown ellagitannin \\
$\mathbf{1 1}$ & 5.8 & $270 / 360$ & 447 & 285 & AP & Kaempferol 3-O-glucoside \\
$\mathbf{1 2}$ & 6.7 & $290 / 320$ & 312 & $135-178$ & AP & Feruloyl glycoside \\
$\mathbf{1 3}$ & 6.7 & $285 / 320$ & 655 & $378-484-543-587-619$ & $\mathrm{R}$ & ND \\
$\mathbf{1 4}$ & 7.1 & $255 / 360$ & 423 & $343-80$ & AP/R & Flavonoid sulfate \\
$\mathbf{1 5}$ & 7.3 & $260 / 370$ & 449 & $403-311-170$ & AP & Eriodictyol hexoside \\
\hline
\end{tabular}

TABLE 3: Pearson's correlation coefficients of antioxidant activities and total phenolic contents ${ }^{\mathrm{a}}$.

\begin{tabular}{lcccc}
\hline & DPPH & ABTS & ORAC & MCA \\
\hline Aerial parts & & & & \\
TPC & $0.9842^{* * *}$ & $0.961^{* *}$ & $0.9594^{* *}$ & $0.6424^{\mathrm{ns}}$ \\
DPPH & & $0.96^{* *}$ & $0.9019^{*}$ & $0.5918^{\mathrm{ns}}$ \\
ABTS & & & $0.9008^{*}$ & $0.7626^{\mathrm{ns}}$ \\
ORAC & & & & $0.6971^{\mathrm{ns}}$ \\
Roots & & & & \\
TPC & $0.9619^{* *}$ & $0.9734^{* *}$ & $0.5506^{\mathrm{ns}}$ & $0.9445^{* *}$ \\
DPPH & & $0.9935^{* * *}$ & $0.5215^{\mathrm{ns}}$ & $0.9456^{* *}$ \\
ABTS & & & $0.4754^{\mathrm{ns}}$ & $0.9745^{* * *}$ \\
ORAC & & & & $0.3109^{\mathrm{ns}}$ \\
\hline
\end{tabular}

${ }^{\mathrm{a}}$ Data represents Pearson's correlation coefficient $R$. ns indicates nonsignificant; * refers to $P<0.05 ; * *$ and $* * *$ indicate significant at $P<0.01$ and $P<0.001$, respectively.

Compound 1 at $m / z 169$ corresponds to gallic acid. It was identified with fragmentation ion at $m / z 125\left([\mathrm{M}-\mathrm{H}-44]^{-}\right)$ corresponding to the loss of carboxylate.

Analysis revealed the presence of another phytochemical with antioxidant properties, hydroxytyrosol (compound 2) in the negative ESI-mode with ions at $\mathrm{m} / z$ 153, and a single diagnostic fragment at $\mathrm{m} / z 123$ corresponding to the formal loss of a formaldehyde unit [30]. Compound 3 (RT $3.9 \mathrm{~min}$ ) shows a profile with $[\mathrm{M}-\mathrm{H}]^{-}$at $m / z 137$, which, under MS/MS conditions, yields fragments at $m / z 93$ characteristic of this compound that is assigned as $p$-hydroxybenzoic acid [31]. In the negative mode, hydroxybenzoic acids produced deprotonated $[\mathrm{M}-\mathrm{H}-44]^{-}$fragment ion via loss of $\mathrm{CO}_{2}$ group from the carboxylic acid moiety [32]. The UV spectra of the hydroxybenzoic acids were quite relevant to their chemical structure.
The heterocyclic ring fragment pathways of flavan-3-ols are through quinone-methide, retro-Diels-Alder, and heterocyclic ring fission [33]. The protonated ion at $m / z 609$ (peak 4) produced MS fragment ions at $\mathrm{m} / z 483$ through heterocyclic ring fission (loss of $\mathrm{C}_{6} \mathrm{H}_{6} \mathrm{O}_{3}$ ), $\mathrm{m} / z 441$ through the retroDiels-Alder fission (loss of $\mathrm{C}_{7} \mathrm{H}_{6} \mathrm{O}_{3}$ ), $\mathrm{m} / z 423$ through the same fission following the loss of one $\mathrm{H}_{2} \mathrm{O}$, and $\mathrm{m} / z 305$ through quinone-methide [33, 34]. Hence, compound 4 was assigned as prodelphinidin B-4. This compound was previously isolated and identified as the main flavonols in tea [35]. However, it was reported here for F. thymifolia for the first time.

Compound 5 (Rt $4.2 \mathrm{~min}$ ) exhibited $[\mathrm{M}-\mathrm{H}]^{-}$ion at $\mathrm{m} / z 635$ with $\lambda_{\max }$ at $280 \mathrm{~nm}$ and fragment at $\mathrm{m} / z 465$ corresponding to loss of gallic acid $m / z 170$ [36]. Therefore, this compound was identified as trigalloyl hexoside.

Peak 6 that gave $[\mathrm{M}-\mathrm{H}]^{-}$ions at $m / z 333$ corresponds to posthumulone which yielded the two fragment ions at $\mathrm{m} / z 289$ and $\mathrm{m} / z 265$ corresponding, respectively, to the characteristic losses of propyl group $\left[\mathrm{M}-\mathrm{H}-\mathrm{C}_{3} \mathrm{H}_{7}\right]$ and prenyl group [M - 68] [37].

Peak 7 (Rt $4.5 \mathrm{~min}$ ) at $\mathrm{m} / \mathrm{z} 449$ is assigned as luteolin 7$O$-glucoside; the $\mathrm{m} / z 449$ ion generated fragment ions at $\mathrm{m} / \mathrm{z}$ 287 , corresponding to luteolin aglycone in structure; and $\mathrm{m} / z$ 431 corresponds to loss of $\mathrm{H}_{2} \mathrm{O}([\mathrm{M}-\mathrm{H}-18])$.

Quercetin-3-O-galactoside (hyperoside, compound 8) was identified by MS/MS analysis in neutral loss of $162 \mathrm{amu}$ (loss of tetrahydroxylated hexose) [38]. Its ion fragments were observed at $m / z 301$ in full scan mode. The observed fragment ions at $m / z 178$ and 151 correspond to quercetin fragmentation pattern [39].

Compound 9 found in aerial parts is speculated as pinoresinol (lignan) with $m / z 357$ and it produced the ion at $\mathrm{m} / z 329$ corresponding to loss of CO [40]. In this context, Harkat et al. [12] previously identified pinoresinol 4-sulfate (sulfated lignan) in F. thymifolia roots. 


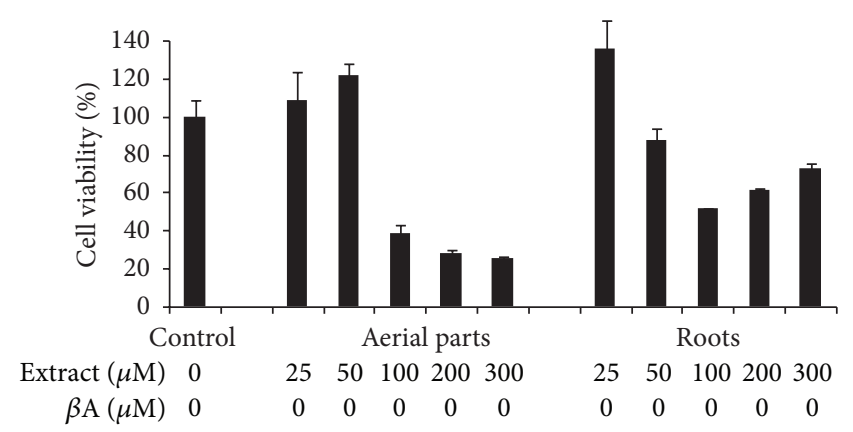

(a)

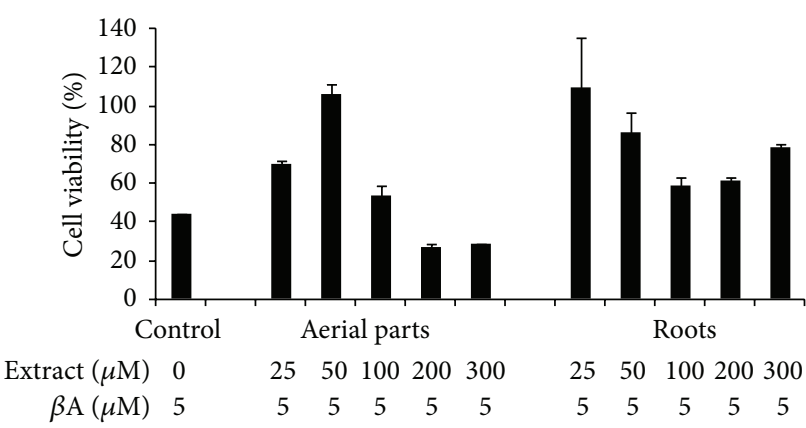

(b)

Figure 2: Cytoprotective effects of EtOAc extracts (a) and neuroprotective activity (b) on A $\beta$-induced toxicity in PC12 cell line. The experiment was repeated three times.

Compound $\mathbf{1 0}$ corresponding to unknown ellagitannin is a phenolic compound with sugar core exhibiting typical features in LC-MS analysis: loss of gallic acid moieties (152 amu), hexahydroxydiphenyl glucose unit (HHDPglucose, $482 \mathrm{amu}$ ), and repetitive loss of water molecules and tendency to form double-charged ions [41]. UV/visible spectrum shows $\lambda_{\max }$ at the range of 290-320 nm. Several ellagitannins are typically detected in this MS spectrum [42].

Furthermore, compound 11 had $[\mathrm{M}-\mathrm{H}]^{-}$at $m / z 447$ with fragment at $m / z 285$ (loss of 162 amu: hexose moiety) and was identified as kaempferol 3-O-glucoside [43].

Compound $12\left([\mathrm{M}-\mathrm{H}]^{-}\right.$at $\left.m / z 312\right)$ has been assigned as feruloyl glycoside. MS/MS spectrum of this compound has shown the characteristic product ion at $\mathrm{m} / z 135$ corresponding to the feruloyl moiety and a fragment at $\mathrm{m} / \mathrm{z}$ 178. Identity of the compounds was verified by characteristic UV spectra showing $\lambda_{\max }$ at 290-320 $\mathrm{nm}$.

Compound 13 remains unidentified. No data corresponding to its mass spectra in the literature and databases was reported. However, peak $\mathbf{1 4}$ has fragment ion $\mathrm{m} / \mathrm{z} 80$ corresponding to sulfate and UV-vis spectrum shape with $\lambda_{\max }$ at 290 and $360 \mathrm{~nm}$ proposed as sulfated flavonoid.

Compound $\mathbf{1 5}$ is identified as eriodictyol hexoside; according to the characterization of $[\mathrm{M}-\mathrm{H}]^{-}$ion at $m / z 449$, it is a flavonoid derivate. All these flavonoids cited were not observed previously in F. thymifolia.

3.4. Neuroprotective Activity of EtOAc Fraction. Due to the strong TPC and the antioxidant capacities of EtOAc fractions, the protective effect of these fractions against $\mathrm{A} \beta$-induced toxicity in PC12 cell line was further investigated. First, the cytotoxic potential of each EtOAc fraction on PC12 cells was measured with the MTT assay. EtOAc fractions of both organs were not cytotoxic at the concentrations of 25 and $50 \mu \mathrm{g} / \mathrm{mL}$ (Figure 2(a)). Treatment of PC12 cells with $5 \mu \mathrm{M} \mathrm{A} \beta_{25-35}$ reduced cell viability about $40 \%$ of control (Figure $2(\mathrm{~b})$ ). Induction of cytotoxicity by $\mathrm{A} \beta_{25-35}$ at $5 \mu \mathrm{M}$ was then used for all subsequent experiments to evaluate the protective effect of the species. F. thymifolia fractions completely reversed the toxic effect of $\mathrm{A} \beta_{25-35}$ (at 25 and $50 \mu \mathrm{g} / \mathrm{mL}$ for aerial parts and roots, resp.), indicating a significant neuroprotective effect of $F$. thymifolia EtOAc fractions. Nevertheless, results displayed a competitive effect at higher concentrations $(>100 \mu \mathrm{g} / \mathrm{mL})$ between the toxicity of $F$. thymifolia on PC12 cells and the protective effect against $\mathrm{A} \beta$-induced toxicity. In fact, this neuroprotective activity is mainly correlated to the nature of phenolic compounds in EtOAc fractions. In this context, several reports have demonstrated that gallic acid and ellagitannins, two major compounds identified in roots, inhibit efficiency $\beta$-amyloid $(\mathrm{A} \beta)$ peptide aggregation in vitro [44], while kaempferol 3$O$-glucoside [45] and $p$-hydroxybenzoic acid [10] were found to possess moderate inhibitory effect on $\mathrm{A} \beta$ aggregation. Zeng et al. [46] showed that hyperoside significantly inhibited $\mathrm{A} \beta_{25-35}$-induced cytotoxicity and apoptosis by reversing $\mathrm{A} \beta$ induced mitochondrial dysfunction, including mitochondrial membrane potential decrease, reactive oxygen species production, and mitochondrial release of cytochrome $c$.

\section{Conclusion}

F. thymifolia species have a high content of phenolic compounds and a good antioxidant and neuroprotective activities; therefore they can be used to treat several diseases in which there is an increase in free radical production. Moreover, the nature and polarity of solvent had a significant impact on the phenolic content and antioxidant activity. Overall, the EtOAc fraction of the halophyte F. thymifolia contained the highest levels of phenolic content and antioxidant activities. It has been established also that HPLC-DADESI-MS is a powerful analytical technique for the separation and detection of phenolics in F. thymifolia. The obtained data indicate qualitatively that EtOAc fraction of $F$. thymifolia is an abundant source of bioactive phytochemicals and it could explain the antioxidant and neuroprotective capacities of this species.

\section{Competing Interests}

The authors declare that there are no competing interests.

\section{Acknowledgments}

This work was supported by the Tunisian Ministry of Higher Education and Scientific Research (LR15CBBC06). 


\section{References}

[1] G. P. Kumar, K. R. Anilakumar, and S. Naveen, "Phytochemicals having neuroprotective properties from dietary sources and medicinal herbs," Pharmacognosy Journal, vol. 7, no. 1, pp. 1-17, 2015.

[2] V. Murugaiyah and M. P. Mattson, "Neurohormetic phytochemicals: an evolutionary-bioenergetic perspective," Neurochemistry International, vol. 89, pp. 271-280, 2015.

[3] A. Dávalos, C. Gómez-Cordovés, and B. Bartolomé, "Extending Applicability of the Oxygen Radical Absorbance Capacity (ORAC-Fluorescein) assay," Journal of Agricultural and Food Chemistry, vol. 52, no. 1, pp. 48-54, 2004.

[4] D. J. Betteridge, "What is oxidative stress?" Metabolism, vol. 49, no. 2, pp. 3-8, 2000.

[5] E. Tellone, A. Galtieri, A. Russo, B. Giardina, and S. Ficarra, "Resveratrol: a focus on several neurodegenerative diseases," Oxidative Medicine and Cellular Longevity, vol. 2015, Article ID 392169, 14 pages, 2015.

[6] S. Kumar, K. K. Maheshwari, and V. Singh, "Protective effects of Punica granatum seeds extract against aging and scopolamine induced cognitive impairments in mice," African Journal of Traditional, Complementary and Alternative Medicines, vol. 6, no. 1, pp. 49-56, 2009.

[7] C. Arias, T. Montiel, R. Quiroz-Báez, and L. Massieu, “ $\beta$ amyloid neurotoxicity is exacerbated during glycolysis inhibition and mitochondrial impairment in the rat hippocampus in vivo and in isolated nerve terminals: implications for alzheimer's disease," Experimental Neurology, vol. 176, no. 1, pp. 163-174, 2002.

[8] A. Y. Abramov, L. Canevari, and M. R. Duchen, “ $\beta$-amyloid peptides induce mitochondrial dysfunction and oxidative stress in astrocytes and death of neurons through activation of NADPH oxidase," Journal of Neuroscience, vol. 24, no. 2, pp. 565-575, 2004.

[9] M. A. Ansari, H. M. Abdul, G. Joshi, W. O. Opii, and D. A. Butterfield, "Protective effect of quercetin in primary neurons against A $\beta(1-42)$ : relevance to Alzheimer's disease," Journal of Nutritional Biochemistry, vol. 20, no. 4, pp. 269-275, 2009.

[10] C. Rivière, T. Richard, X. Vitrac, J.-M. Mérillon, J. Valls, and J.P. Monti, "New polyphenols active on $\beta$-amyloid aggregation," Bioorganic and Medicinal Chemistry Letters, vol. 18, no. 2, pp. 828-831, 2008.

[11] M. K. Wided, C. Feten, M. Rawya et al., "Antioxidant and antimicrobial properties of Frankenia thymifolia desf. fractions and their related biomolecules identification by gas chromatography/ mass spectrometry (GC/MS) and high performance liquid chromatography (HPLC)," Journal of Medicinal Plant Research, vol. 5, no. 24, pp. 5754-5765, 2011.

[12] H. Harkat, H. Haba, L. Marcourt, C. Long, and M. Benkhaled, "An unusual lignan sulfate and aromatic compounds from Frankenia thymifolia Desf," Biochemical Systematics and Ecology, vol. 35, no. 3, pp. 176-179, 2007.

[13] V. L. Singleton and J. A. Rossi, "Colorimetry of total phenolics with phosphomolybdic-phosphotungstic acid reagents," American Journal of Enology and Viticulture, vol. 16, pp. 144-158, 1965.

[14] M. S. Blois, "Antioxidant determinations by the use of a stable free radical," Nature, vol. 181, no. 4617, pp. 1199-1200, 1958.

[15] R. Re, N. Pellegrini, A. Proteggente, A. Pannala, M. Yang, and C. Rice-Evans, "Antioxidant activity applying an improved ABTS radical cation decolorization assay," Free Radical Biology and Medicine, vol. 26, no. 9-10, pp. 1231-1237, 1999.
[16] T. C. P. Dinis, V. M. C. Madeira, and L. M. Almeida, "Action of phenolic derivatives (acetaminophen, salicylate, and 5aminosalicylate) as inhibitors of membrane lipid peroxidation and as peroxyl radical scavengers," Archives of Biochemistry and Biophysics, vol. 315, no. 1, pp. 161-169, 1994.

[17] B. Ou, M. Hampsch-Woodill, and R. L. Prior, "Development and validation of an improved oxygen radical absorbance capacity assay using fluorescein as the fluorescent probe," Journal of Agricultural and Food Chemistry, vol. 49, no. 10, pp. 4619-4626, 2001.

[18] A. Fernandes de Oliveira, L. Sousa Pinheiro, C. Souto Pereira et al., "Total phenolic content and antioxidant activity of some malvaceae family species," Antioxidants, vol. 1, no. 1, pp. 33-43, 2012.

[19] M. P. Kähkönen, A. I. Hopia, H. J. Vuorela et al., "Antioxidant activity of plant extracts containing phenolic compounds," Journal of Agricultural and Food Chemistry, vol. 47, no. 10, pp. 3954-3962, 1999.

[20] M. A. Anagnostopoulou, P. Kefalas, V. P. Papageorgiou, A. N. Assimopoulou, and D. Boskou, "Radical scavenging activity of various extracts and fractions of sweet orange peel (Citrus sinensis)," Food Chemistry, vol. 94, no. 1, pp. 19-25, 2006.

[21] A. Cakir, A. Mavi, A. Yildirim, M. E. Duru, M. Harmandar, and C. Kazaz, "Isolation and characterization of antioxidant phenolic compounds from the aerial parts of Hypericum hyssopifolium L. by activity-guided fractionation," Journal of Ethnopharmacology, vol. 87, no. 1, pp. 73-83, 2003.

[22] M. Saada, H. Falleh, I. Jalleli, M. Snoussi, and R. Ksouri, "Phenolic profile, biological activities and fraction analysis of the medicinal halophyte Retama raetam," South African Journal of Botany, vol. 94, pp. 114-121, 2014.

[23] J. Tabart, C. Kevers, A. Sipel, J. Pincemail, J.-O. Defraigne, and J. Dommes, "Optimisation of extraction of phenolics and antioxidants from black currant leaves and buds and of stability during storage," Food Chemistry, vol. 105, no. 3, pp. 1268-1275, 2007.

[24] G. Surget, V. Stiger-Pouvreau, K. Le Lann et al., "Structural elucidation, in vitro antioxidant and photoprotective capacities of a purified polyphenolic-enriched fraction from a saltmarsh plant," Journal of Photochemistry and Photobiology B: Biology, vol. 143, pp. 52-60, 2015.

[25] L. J. Lizcano, F. Bakkali, M. B. Ruiz-Larrea, and J. I. RuizSanz, "Antioxidant activity and polyphenol content of aqueous extracts from Colombian Amazonian plants with medicinal use," Food Chemistry, vol. 119, no. 4, pp. 1566-1570, 2010.

[26] R. S. Britton, K. L. Leicester, and B. R. Bacon, "Iron toxicity and chelation therapy," International Journal of Hematology, vol. 76, no. 3, pp. 219-228, 2002.

[27] G. Minotti and S. D. Aust, "Redox cycling of iron and lipid peroxidation," Lipids, vol. 27, no. 3, pp. 219-226, 1992.

[28] P. Costa, S. Gonçalves, P. Valentão, P. B. Andrade, N. Coelho, and A. Romano, "Thymus lotocephalus wild plants and in vitro cultures produce different profiles of phenolic compounds with antioxidant activity," Food Chemistry, vol. 135, no. 3, pp. 12531260, 2012.

[29] N. Babbar, H. S. Oberoi, D. S. Uppal, and R. T. Patil, “Total phenolic content and antioxidant capacity of extracts obtained from six important fruit residues," Food Research International, vol. 44, no. 1, pp. 391-396, 2011.

[30] L. Gentile and N. A. Uccella, "Selected bioactives from callus cultures of olives (Olea europaea L. Var. Coratina) by LC-MS," Food Research International, vol. 55, pp. 128-136, 2014. 
[31] S. A. O. Santos, P. C. R. O. Pinto, A. J. D. Silvestre, and C. P. Neto, "Chemical composition and antioxidant activity of phenolic extracts of cork from Quercus suber L.," Industrial Crops and Products, vol. 31, no. 3, pp. 521-526, 2010.

[32] J. Sun, F. Liang, Y. Bin, P. Li, and C. Duan, "Screening non-colored phenolics in red wines using liquid chromatography/ultraviolet and mass spectrometry/mass spectrometry libraries," Molecules, vol. 12, no. 3, pp. 679-693, 2007.

[33] L. Gu, M. A. Kelm, J. F. Hammerstone et al., "Screening of foods containing proanthocyanidins and their structural characterization using LC-MS/MS and thiolytic degradation," Journal of Agricultural and Food Chemistry, vol. 51, no. 25, pp. 7513-7521, 2003.

[34] J. Dou, V. S. Y. Lee, J. T. C. Tzen, and M.-R. Lee, "Identification and comparison of phenolic compounds in the preparation of oolong tea manufactured by semifermentation and drying processes," Journal of Agricultural and Food Chemistry, vol. 55, no. 18, pp. 7462-7468, 2007.

[35] A. Kiehne, C. Lakenbrink, and U. H. Engelhardt, "Analysis of proanthocyanidins in tea samples: I. LC-MS results," Zeitschrift fur Lebensmittel-Untersuchung und -Forschung, vol. 205, no. 2, pp. 153-157, 1997.

[36] I. M. Abu-Reidah, M. S. Ali-Shtayeh, R. M. Jamous, D. ArráezRomán, and A. Segura-Carretero, "HPLC-DAD-ESI-MS/MS screening of bioactive components from Rhus coriaria L. (Sumac) fruits," Food Chemistry, vol. 166, pp. 179-191, 2015.

[37] X. Zhang, X. Liang, H. Xiao, and Q. Xu, "Direct characterization of bitter acids in a crude hop extract by liquid chromatographyatmospheric pressure chemical ionization mass spectrometry," Journal of the American Society for Mass Spectrometry, vol. 15, no. 2, pp. 180-187, 2004.

[38] F. Sánchez-Rabaneda, O. Jáuregui, I. Casals, C. AndrésLacueva, M. Izquierdo-Pulido, and R. M. Lamuela-Raventós, "Liquid chromatographic/electrospray ionization tandem mass spectrometric study of the phenolic composition of cocoa (Theobroma cacao)," Journal of Mass Spectrometry, vol. 38, no. 1, pp. 35-42, 2003.

[39] Z. Charrouf, M. Hilali, O. Jauregui, M. Soufiaoui, and D. Guillaume, "Separation and characterization of phenolic compounds in argan fruit pulp using liquid chromatographynegative electrospray ionization tandem mass spectroscopy," Food Chemistry, vol. 100, no. 4, pp. 1398-1401, 2007.

[40] P. C. Eklund, M. J. Backman, L. Å. Kronberg, A. I. Smeds, and R. E. Sjöholm, "Identification of lignans by liquid chromatography-electrospray ionization ion-trap mass spectrometry," Journal of Mass Spectrometry, vol. 43, no. 1, pp. 97-107, 2008.

[41] A. T. Hukkanen, H. I. Kokko, A. J. Buchala et al., "Benzothiadiazole induces the accumulation of phenolics and improves resistance to powdery mildew in strawberries," Journal of Agricultural and Food Chemistry, vol. 55, no. 5, pp. 1862-1870, 2007.

[42] K. Hanhineva, I. Rogachev, H. Kokko et al., "Non-targeted analysis of spatial metabolite composition in strawberry (Fragaria $\times$ ananassa) flowers," Phytochemistry, vol. 69, no. 13, pp. 24632481, 2008.

[43] M. Kajdžanoska, V. Gjamovski, and M. Stefova, "HPLC-DADESI-MSn identification of phenolic compounds in cultivated strawberries from Macedonia," Macedonian Journal of Chemistry and Chemical Engineering, vol. 29, no. 2, pp. 181-194, 2010.
[44] T. Sylla, L. Pouységu, G. Da Costa, D. Deffieux, J.-P. Monti, and S. Quideau, "Gallotannins and tannic acid: first chemical syntheses and in vitro inhibitory activity on Alzheimer's amyloid $\beta$-peptide aggregation," Angewandte Chemie, vol. 127, pp. 83358339, 2015.

[45] J. T. T. Zhu, R. C. Y. Choi, G. K. Y. Chu et al., "Flavonoids possess neuroprotective effects on cultured pheochromocytoma PC12 cells: a comparison of different flavonoids in activating estrogenic effect and in preventing $\beta$-amyloid-induced cell death," Journal of Agricultural and Food Chemistry, vol. 55, no. 6, pp. 2438-2445, 2007.

[46] K.-W. Zeng, X.-M. Wang, H. Ko, H. C. Kwon, J. W. Cha, and H. O. Yang, "Hyperoside protects primary rat cortical neurons from neurotoxicity induced by amyloid $\beta$-protein via the PI3K/Akt/Bad/Bcl XL-regulated mitochondrial apoptotic pathway," European Journal of Pharmacology, vol. 672, no. 1-3, pp. 45-55, 2011. 


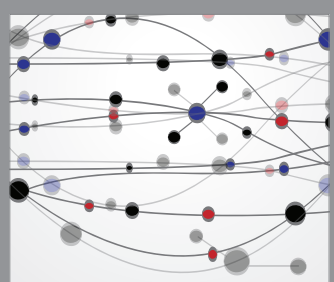

The Scientific World Journal
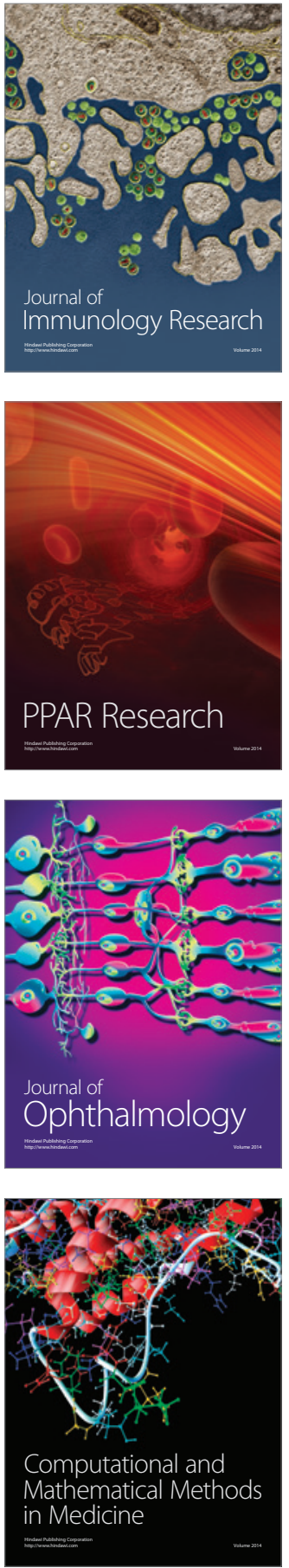

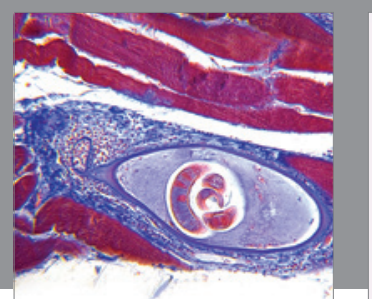

Gastroenterology Research and Practice

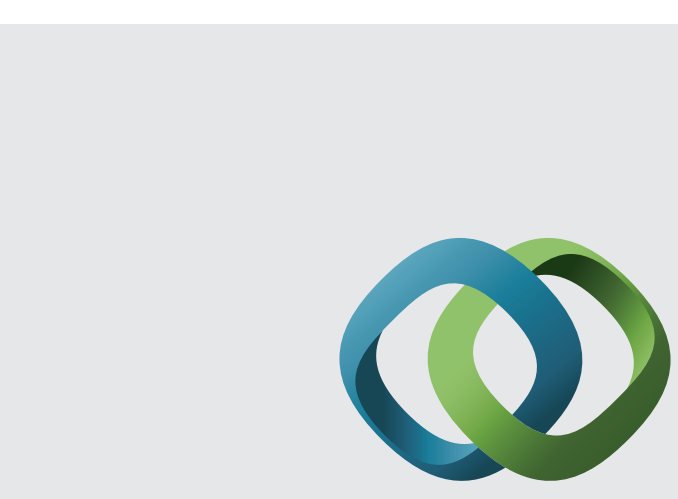

\section{Hindawi}

Submit your manuscripts at

http://www.hindawi.com
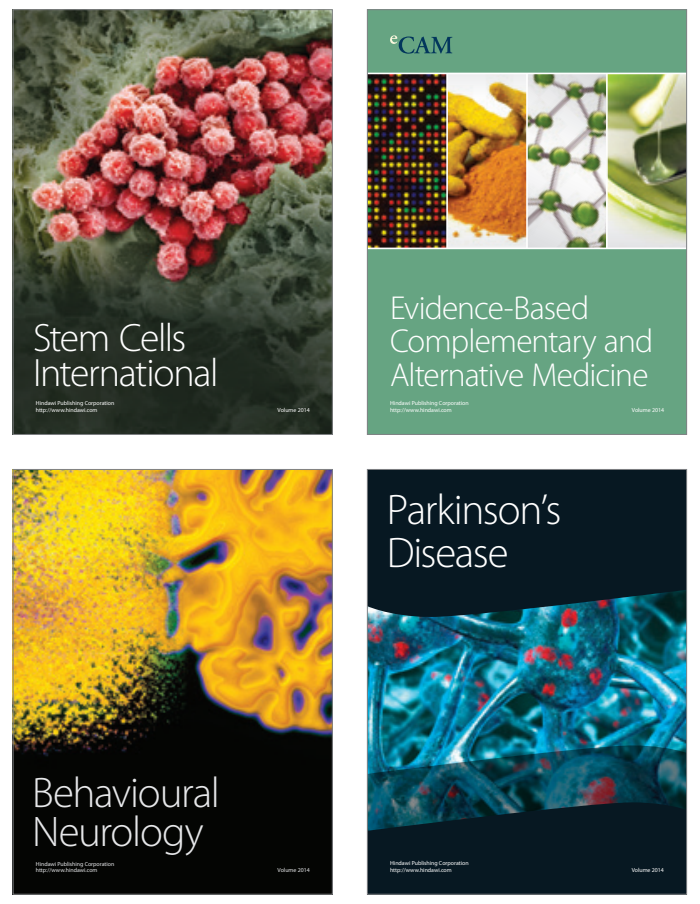
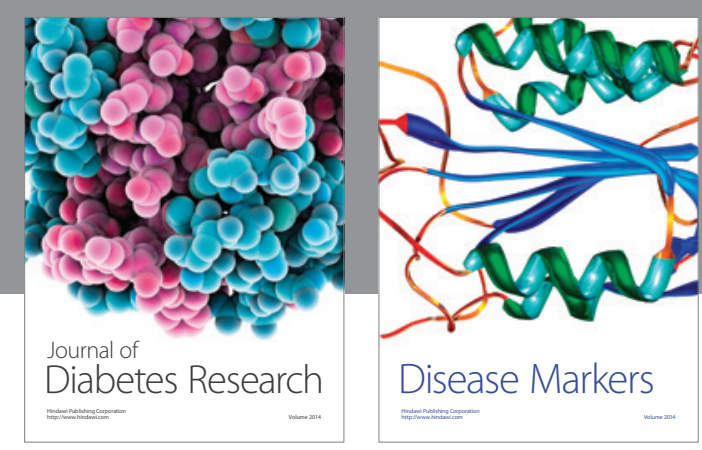

Disease Markers
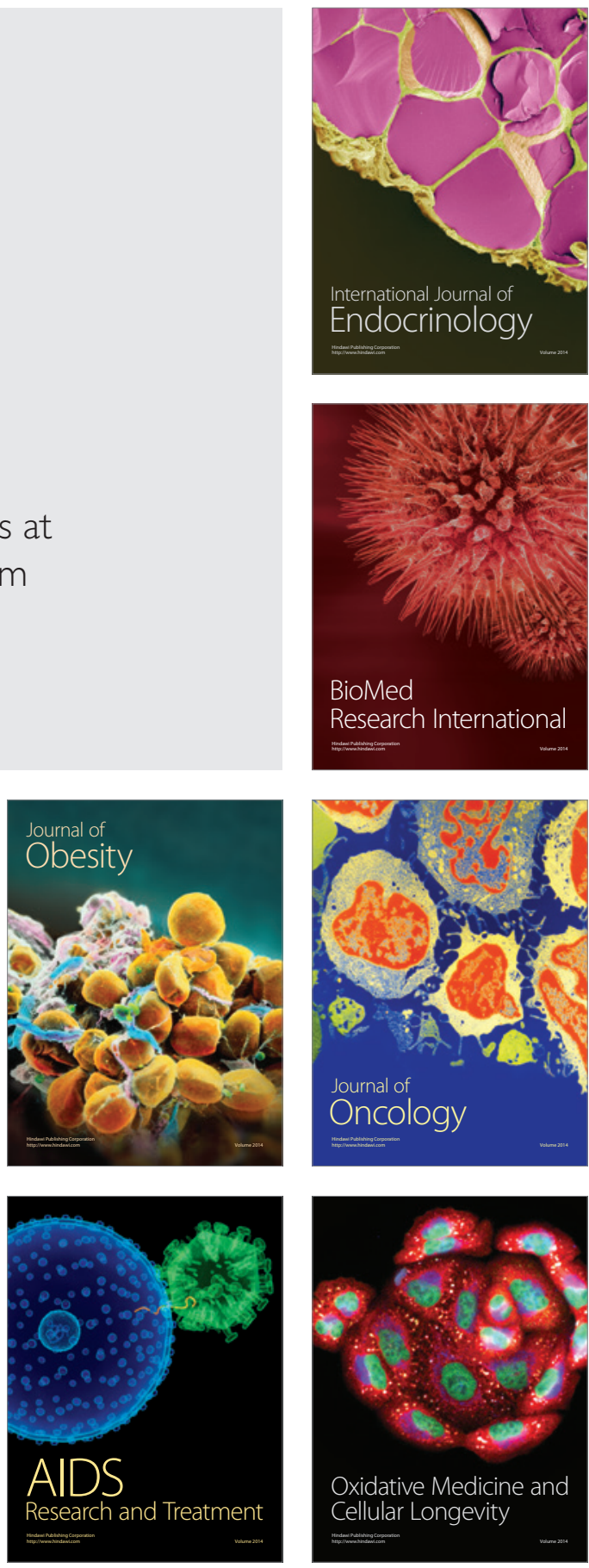